\title{
NEEDS OF HOSPITALIZED SCHIZOPHRENIC PATIENTS IN THE NORTH MORAVIA AND THE CZECH PART OF SILESIA
}

\author{
Jiřina Hosáková ${ }^{1}$, Ladislav Hosák ${ }^{2}$
}

Institute of Nursing, Faculty of Public Policies, Silesian University in Opava, Czech Republic ${ }^{1}$; Department of Psychiatry, Charles University in Prague, Faculty of Medicine in Hradec Králové and University Hospital Hradec Králové, Czech Republic $^{2}$

\begin{abstract}
Summary: Objectives: The main aim of the study was to investigate the physiological and social needs of patients hospitalized with schizophrenia to uncover potential issues in these areas. Methods: The relevant self-evaluating CANSAS questionnaire for physiological and social needs was used by nurses in a cohort of hospitalized schizophrenic patients undergoing rehabilitation before discharge from the mental hospital. Results: Two hundred and forty-four patients (women $\mathrm{N}=115$ ) aged 18-58 years were involved in the study. Intimate relations, financial matters, treatment of psychotic symptoms, and sexual life were among the most pressing physiological and social needs in our study subjects. Conclusion: The results of our study should stimulate psychiatric nurses in their effort not only to detect but also address the problems of schizophrenic patients concerning unfulfilled needs.
\end{abstract}

Keywords: Schizophrenia; Physiological and Social Needs; Psychiatric Nursing; Mental Health Care Reform

\section{Introduction}

Schizophrenia is one of the most serious mental disorders. It affects around $0.3-0.7 \%$ of people at some point in their life (4). Delusions, hallucinations, disorganized thinking, abnormal motor behavior, negative symptoms and cognitive deficit are among the most striking symptoms of schizophrenia. These psychopathological phenomena impair the patients' ability to act comprehensibly, function in social relationships, find and maintain a paid job, and live up to natural expectations (8).

According to Maslow's hierarchy of needs, physiological needs of a human being represent a physiological call of nature which must be met for the subject to live and for his or her health status not to be endangered (3). Social needs are among the so-called "higher needs" and comprise the needs for social contact and support, love, and social self-assertion. The physiological as well as social needs of people suffering from schizophrenia are typically under-accomplished (4).

The purpose of the study was to assess the physiological and social needs of hospitalized schizophrenia patients. This has recently become a "hot" topic in the Czech Republic due to planned mental health care reform. The reform seeks intensive expansion of extramural psychiatric services and extensive involvement of psychiatric nurses in the treatment and rehabilitation of people with serious mental disorders, including schizophrenia (7).

\section{Subjects and Methods}

\section{Subjects}

Hospitalized patients suffering from schizophrenia at the Mental Hospital Opava, Czech Republic from the period of September 2011-June 2014 were asked to participate. The North Moravia and the Czech part of Silesia are the catchment area of this large psychiatric institution. The following inclusion criteria were applied: Age 18-65 years, diagnosis of schizophrenia (F20 according to the ICD-10 classification), voluntary treatment in the hospital, and a willingness to participate in the research. The patients were hospitalized at an open ward mostly aimed at rehabilitation and resocialization. They had already undergone acute pharmacological treatment for schizophrenic episode at a locked psychiatric ward several weeks prior.

We did not examine healthy volunteers because the previous research employing the assessment method of quality of life and needs of the study subjects had already been carried out in the Czech Republic, and the literature allowed us ample access to data concerning the results (2).

\section{Methods}

Sociodemographic data on the study's participants (age, gender, education, occupation, family status and number of 
psychiatric hospitalizations in the patient's life) were obtained from medical records.

We used the Camberwell Assessment of Need questionnaire - the short version (CANSAS) - for every study subject. This tool is intended to survey the physiological and social needs of mentally ill individuals, i.e. whether the needs are met or not. CANSAS includes 22 items related to housing conditions, daily activities, physical health, mental problems, threats to the patient or other people, substance abuse, friends, sexuality, care of children, education, transportation, or finances. Each item is assessed by the responder as to whether this need is satisfied or not (non-existent need/no serious problem $=0$ points; the need has recently been addressed with the help of professional caretakers $=1$ point; the need has not been fulfilled $=2$ points). This means that for items with 1 or 2 points, professional help should be continued (1 point) or applied anew (2 points). The Camberwell Assessment of Need was first introduced in 1995 and is described in detail elsewhere (5). A Czech version of CANSAS has also been validated (6).

The CANSAS questionnaire was applied and its significance was explained to the patients by psychiatric nurses, participating in the research.

\section{Statistics}

We used the two-sample Student's t-test. If individual parameters were analyzed (age, employment status, living with a partner), we applied the non-parametric Wilcoxon test and Kruskal-Wallis test. A result was considered statistically significant if $\mathrm{p}<0.05$. We used the Stata v. 13 statistical program.

\section{Ethical issues}

The work was approved by the Ethics Committee, Faculty of Medicine, University of Ostrava, Czech Republic on the 20th of June, 2011 (EK 3/2011). The subjects voluntarily gave their informed consent to participate. The study was performed in accordance with the principles of the Declaration of Helsinki of 1975, as revised in 2000.

\section{Results}

\section{Sociodemographic data on the study sample}

The total number of schizophrenia patients included into the study was 244 (women $N=115$ ). Sociodemographic data on the study sample are stated in detail in Table 1.

To sum up, a typical participant was a male aged 18-29, living in a city of 10,000-50,000 inhabitants, with a highschool education, receiving a disability pension, with an "average" economic background, single, childless, and recently hospitalized at a psychiatric ward for the 2 nd-3rd time in his life.
Tab. 1: Sociodemographic data on the study sample of schizophrenia patients $(\mathrm{N}=244$; women $\mathrm{N}=115)$.

\begin{tabular}{|c|c|}
\hline Variable & $\begin{array}{c}\text { Proportion of the study } \\
\text { sample }(\%)\end{array}$ \\
\hline $\begin{array}{l}\text { Age range (years) } \\
\begin{array}{l}18-29 \\
30-44 \\
45-58\end{array}\end{array}$ & $\begin{array}{l}52 \\
37 \\
11\end{array}$ \\
\hline $\begin{array}{l}\text { Residence (inhabitants) } \\
\text { Less than } 10,000 \\
10,000-50,000 \\
50,000-100,000 \\
100,000 \text { and more }\end{array}$ & $\begin{array}{l}24 \\
37 \\
22 \\
17\end{array}$ \\
\hline $\begin{array}{l}\text { Education } \\
\text { Primary school } \\
\text { Vocational school } \\
\text { High school } \\
\text { University }\end{array}$ & $\begin{array}{r}8 \\
36 \\
46 \\
10\end{array}$ \\
\hline $\begin{array}{l}\text { Employment } \\
\text { Disability pension } \\
\text { Unemployed } \\
\text { Employed } \\
\text { Student } \\
\text { Retiree } \\
\text { Entrepreneur } \\
\text { Maternity leave } \\
\text { Housewife } \\
\text { Not stated }\end{array}$ & $\begin{array}{r}42 \\
25 \\
13 \\
11 \\
4 \\
2 \\
1 \\
1 \\
1\end{array}$ \\
\hline $\begin{array}{l}\text { The current financial situation } \\
\text { Substantially above-average } \\
\text { Moderately above-average } \\
\text { Average } \\
\text { Moderately below-average } \\
\text { Substanitally below-average }\end{array}$ & $\begin{array}{r}1 \\
5 \\
41 \\
38 \\
15\end{array}$ \\
\hline $\begin{array}{l}\text { Marital status } \\
\text { Single } \\
\text { Married or a similar relationship } \\
\text { Divorced }\end{array}$ & $\begin{array}{l}59 \\
27 \\
14\end{array}$ \\
\hline $\begin{array}{c}\text { Children } \\
\text { No } \\
\text { Yes }\end{array}$ & $\begin{array}{l}70 \\
30 \\
\end{array}$ \\
\hline $\begin{array}{l}\text { Order of the current } \\
\text { psychiatric hospitalization } \\
\text { 1st } \\
\text { 2nd-3rd } \\
4 \text { th-5th } \\
6 \text { th or further }\end{array}$ & $\begin{array}{l}30 \\
34 \\
19 \\
17\end{array}$ \\
\hline
\end{tabular}

\section{Physiological and social needs of the patients}

According to the CANSAS questionnaire results, intimate relations, financial situation and treatment of psychotic symptoms were among the most unfulfilled items in general, while in the subgroup of men sexual life was also stated ( $p=0.016$; two-sample Student's t-test). This was not influ- 
enced by age or employment status ( $p=$ NS; Wilcoxon test, Kruskal-Wallis test). On the other hand, patients living with a partner more often perceived their physiological and social needs to be met in comparison with study subjects who were single $(\mathrm{p}<0.05$; Wilcoxon test). The CANSAS results of schizophrenia patients are shown in Table 2.

Tab. 2: The Camberwell Assessment of Need questionnaire (CANSAS) - results in 244 patients with schizophrenia.

\begin{tabular}{|l|c|c|}
\hline \multicolumn{1}{|c|}{ Item } & Arithm. mean & Sd \\
\hline Housing & 0.16 & 0.36 \\
\hline Nourishment & 0.08 & 0.28 \\
\hline Housekeeping & 0.11 & 0.32 \\
\hline Self-care & 0.06 & 0.25 \\
\hline Daily activities & 0.28 & 0.66 \\
\hline Physical health & 0.22 & 0.41 \\
\hline Psychotic symptoms & 1.06 & 0.98 \\
\hline Informations on health & 0.23 & 0.42 \\
\hline Mental problems & 0.72 & 0.55 \\
\hline Threat to oneself & 0.40 & 0.49 \\
\hline Threat to others & 0.34 & 0.86 \\
\hline Alcohol & 0.19 & 0.39 \\
\hline Illegal drugs & 0.21 & 0.41 \\
\hline Friends & 0.46 & 0.84 \\
\hline Intimate relationships & 0.96 & 1.10 \\
\hline Sexuality & 0.93 & 1.09 \\
\hline Care of children & 0.24 & 0.43 \\
\hline Education & 0.08 & 0.28 \\
\hline Telephoning & 0.04 & 0.21 \\
\hline Transportation & 0.30 & 0.67 \\
\hline Finances & 0.51 & 0.79 \\
\hline Financial benefits & 1.00 & 2.13 \\
\hline
\end{tabular}

\section{Discussion}

Our patients mostly indicated that their unmet physiological and social needs involved social relations, finances, treatment of psychotic symptoms, and sexual life, all of which is understandable. As stated above in the sociodemographic data section, a typical respondent in the study was a single male, receiving a disability pension, and hospitalized for schizophrenia. Our results are similar to the ones ascertained by Wennstrom et al. (9). The authors investigated 741 outpatients with schizophrenia and other psychotic disorders in Sweden. The main difference in the Wennstrom's study sample was that finances were not seen as such a pressing issue as in our study. This may be due to mentally ill people in Sweden being in better position financially than those in the Czech Republic.

Our study also concurred with Brain et al. (1) in revealing the importance of close social relationships in the lives of schizophrenic patients. The authors studied 111 outpatients with schizophrenia and schizophrenia-like psychosis. If the study subjects felt stigmatized and discriminated against, social relationships (including intimate ones) were perceived as the most important domain. On the other hand, a quality partnership may help the patient to overcome his or her troubles better.

The subjective assessment of needs as well as the use of the CANSAS questionnaire only for hospitalized schizophrenic patients represents the limitations of our study. A more comprehensive view would be obtained if objective tools were utilized not only in inpatients but also on an outpatient basis. This attitude may be employed in future research.

The patients suffering from schizophrenia and this mental disorder itself are specific, different from other mental disorders (for example major depression, anxiety disorders) or physical diseases. A lack of insight in schizophrenia is typical, which may distort the subjective evaluation of psychotic symptoms or feeling of the disease in general. This should be taken into consideration in the interpretation of the study results.

On the other hand, a relatively large and homogenous study sample is one of the strong points of our research.

\section{Conclusions}

The practical outcome of our study can be to stimulate psychiatric nurses in their effort to continuously detect and take care of problems concerning the unmet needs of patients with schizophrenia. Further research in this field could be performed by monitoring the needs of schizophrenic patients before and after the systematic education by psychiatric nurses and optimization of nursing care. This is especially important in the Czech Republic, where legislative reform of mental health care emphasizing community care and psychiatric nursing has recently been implemented.

\section{References}

1. Brain C, Sameby B, Allerby K, et al. Stigma, discrimination and medication adherence in schizophrenia: results from the Swedish COAST study. Psychiat Res 2014; 220: 811-7.

2. Dragomirecka E, Bartonova J, Motlova L, et al. SQUALA. Prirucka pro uzivatele české verze Dotazniku subjektivni kvality zivota SQUALA. 1st ed. Prague: Psychiatric Center Prague, 2006: 68.

3. Maslow AH, Abraham H. A Theory of Human Motivation. Psychol Rev 1943; 50: 370-6.

4. van Os J, Kapur S. Schizophrenia. Lancet 2009; 374: 635-45. 
5. Phelan M, Slade M, Thornicroft G, et al. The Camberwell Assessment of Need: the validity and reliability of an instrument to assess the needs of people with severe mental illness. Br J Psychiat 1995; 167: 589-95.

6. Probstova V, Selepova P, Dragomirecka E, et al. Pece o dusevni zdravi. Metody hodnoceni. CAN: Camberwellske setreni potreb. 1st ed. Prague: Centrum pro rozvoj pece o dusevni zdravi, 2006: 63 .
7. Tresnak P. Taking mental health into the community. Bull World Health Organ 2014; 92: 702-3.

8. Weinberger DR, Harrison P. Schizophrenia. 3rd ed. Oxford: Wiley-Blackwell, 2011: 722 .

9. Wennstrom E, Sorbom D, Wiesel FA. Factor structure in the Camberwell Assessment of Need. Br J Psychiat 2004; 185: 505-10.

Received: 02/07/2015

Accepted in revised form: 26/08/2015

\section{Corresponding author:}

Jiřina Hosáková, MSc., The Institute of Nursing, Hauerova 4, 74601 Opava, Czech Republic; e-mail: jirina.hosakova@ fvp.slu.cz 